\title{
O Impacto do Sistema de Transporte sobre o Espaço Urbano e seu Controle
}

\author{
Andreina Nigriello
}

O controle do impacto sobre o espaço urbano de melhorias efetuadas no sistema de transporte pressupōe o entendimento da interaçāo entre o uso e ocupação do solo e a acessibilidade. Essa interação e seus efeitos estão confirmados em estudos estatísticos do impacto da linha Norte-Sul do metrô de São Paulo sobre o espaço urbano.

Para o controle desses efeitos são propostas algumas estratégias visando: maior justiça social na distribuição dos beneffcios indiretos vinculados aos investimentos públicos no setor de transporte; a criação de novas fontes de financiamento para o setor, e a redução do afastamento da população de baixa renda das áreas diretamente atendidas pelas melhorias de transporte.

\footnotetext{
The control of the impact caused by improvements made in the transportation system on urban areas presumes the recognition of the interaction between soil utilization and occupation and access thereto. Said interaction and its effects can be found in statistical studies concerned with the impact caused by São Paulo subway North-South line on urban areas, and the purpose thereof is to: develop a greater sense of social equity in the distribution of indirect benefits associated with public investments in the transportation sector; create new financing sources for said sector; and reduce the withdrawal of poor people from areas directly served by improved transportation system.
}

Artigo elaborado com base na Tese de Doutorado "Conservar para desenvolver", apresentada em junho de 1987.

Orientador. Prof. Dr. Jorge Dantas. 


\section{Introdução}

Para os investigadores da dinâmica de expansão e transformação do espaço urbano, poucas relaçōes são tão evidentes quanto a que se estabelece entre o uso e ocupação do solo e a oferta de transporte. Inúmeras pesquisas foram efetuadas no estudo dessa interação, em geral motivadas pela necessidade de dotar o planejamento urbano e de transporte de instrumentos que simulem o impacto de alterações significativas no nivel de acessibilidade sobre o espaço edificado, a tipologia de usos do solo e a demanda futura de transporte. A elaboração de tais modelos de simulaçāo - que orientam a definição de intervençōes no sistema de transporte visando o atendimento da demanda de viagens e a ordenação do espaço urbano são a principal, mas não a única, finalidade desses estudos.

Parte desses estudos foi elaborada objetivando evidenciar a captação privada da valorização imobiliária resultante de investimentos no sistema de transporte e propôr medidas que viabilizem sua recuperação, mesmo se parcial, pelo setor público. Outros, focalizaram os efeitos da captação dessa valorização imobiliária sobre o espaço já edificado e a população de baixa renda ${ }^{1}$.

Neste artigo apresenta-se uma sintese da dinâmica da interação entre o uso e ocupação do solo e a oferta de transporte (acessibilidade); citam-se as conclusōes de estudos emplricos sobre esta interação, desenvolvidos pesquisando-se estatisticamente os efeitos da implantação da linha Norte-Sul do metrô de São Paulo sobre o espaço urbano adjacente; finalmente, propōem-se medidas para o Poder Público recuperar parte da valorização imobiliária vinculada a seus investimentos no sistema de transporte e outras, para fixação da população de baixa renda e conservaçāo das edificaçōes nas áreas mais valorizadas.

\section{A Dinâmica da Interação do Uso e Ocupação do Solo com a Acessibilidade}

Nos espaços beneficiados por melhorias no sistema de transporte, que implicam em geral em investimentos públicos significativos, os aumentos nos niveis de acessibilidade aliam-se a maiores graus de desenvolvimento urbano local. Esse desenvolvimento é o resultado de um processo que se estabelece a partir de expectativas de maiores economias de localização e de melhor qualidade de vida que população e atividades associam a melhorias de transporte, como, por exemplo, uma nova via expressa ou mais uma linha de metrô. Tais expectativas repercutem inicialmente com um aumento no

(1) ALQUIER, F. Contribution à l'etude de la rene foncière sur les terrains urbains. Espace et Sociêtés (2): 75-87 mar., 1971.

BATISTUZZO, A. R. de C.; PACHECO, R. S. V. M. O processo de valorizaçăo dos terrenos em uma área de intervençăo pública concentrada: Vila do Encontro. Espaço e Debates. São Paulo (2): 19-59, maío 1981.

FOLIN, M. La ciudad del capital. México, D. F., Gili, 1977.

LIPIETZ, A. Le tribut foncier urbain. Parls, François Maspero, 1974.

LOJKINE, J. O Estado capitalista e a questăo urbana. Sáo Paulo, Martins Fontes, 1981.

NIGRIELO, A. Pesqulsa Bibliográfica. In: $O$ valor do solo e sua relaçáo com a acessibilidade. (Estudo do impacto da Implantaçăo da IInha NorteSul do metrồ de Såo Paulo sobre o mercado imobiliárlo). Rio de Janeiro, 1977. Dissertaçāo Mestrado - COPPE/UFRJ. p. 4-75.

SAYAD, J. Preço da terra e mercados financeiros. Săo Paulo, FIPEJUSP, 1977.

TOPALOV, C. Capital et proprieté foncière. Paris, CSU, 1973. p. 208-209.

VIEIRA DA CUNHA, P.; SMOLKA, M. O Notas crfticas sobre a relaçăo entre rendas fundiárias e 0 uso do solo urbano. Såo Paulo, FUNDAP, 1978. preço do solo local, o que por sua vez torna atrativa para os empreendedores imobiliários a relação capital investido/beneficios esperados. Ou seja, os investimentos públicos em transporte criam oportunidade para captação da valorização por eles gerada no local, através da construção e comercialização de novas edificações. Como conseqüência, aumenta a ocupação do solo na área de influência direta das melhorias no sistema de transporte, com a edificação dos vazios urbanos e a renovaçāo das construçōes existentes. Decorrem também alteraçōes no uso do solo, com a substituição das atividades existentes por outras mais rentáveis, em condiçōes de pagar os novos custos de localização.

Da mesma forma, o mercado local de habitação passa a ser dirigido a uma população de maior poder aquisitivo. Cabe observar que tais transformaçōes, realizadas em gera! sem a orientação de planos urbanísticos, nem sempre são as mais adequadas ao espaço urbano em seu todo, produzindo carências na oferta dos demais serviços e equipamentos urbanos e maiores custos de gestão da cidade. Uma participação mais direta do Poder Público nesse processo de transformação do espaço urbano propicia a renovaçāo planejada das áreas beneficiadas e também a recuperaçāo de parte da valorizaçāo causada pelos investimentos em transporte, gerando recursos para o setor. 


\section{Impacto da Linha Norte-Sul do Metrô de São Paulo no Espaço Urbano e seus Reflexos no Perfil dos Usuários do Serviço}

Os resultados de estudos emplricos sobre as alteraçōes no mercado imobiliário e no uso e ocupação do solo, provocadas pela linha Norte-Sul do metrô, em São Paulo, comprovam uma vez mais a interaçăo entre o sistema de transporte e o espaço urbano ${ }^{2}$.

\section{O Impacto sobre o Preço do Solo}

O impacto sobre o preço do solo atribulvel a alteraçōes na acessibilidade introduzidas pela linha Norte-Sul foi mensurado confrontando-se amostras de ofertas de terreno de áreas onde mais de $70 \%$ do total de viagens são realizadas por metrô, de forma integrada ou não a outros modos, com amostras colhidas em áreas semelhantes às primeiras, mas não atendidas por esse serviço. Através dessa comparação - realizada com dados de 1968 e 1976, respectivamente, antes do decreto de implantação da linha e um ano após sua inauguração - e de correlaçōes simples e múltiplas, efetuadas entre os preços de mercado dos terrenos e indicadores do grau de acessibilidade (tempo de viagem), grau de urbanização ('ndices da planta de valores), caracter(sticas ffsicas dos lotes (frente, profundidade), restriçōes legais para o aproveitamento do solo (lei de zoneamento) e renda média familiar, identificou-se: alta correlação entre o preço do solo e o nivel de acessibilidade; aumento geral do preço do solo nas áreas atendidas pela linha; maior aumento do preço do solo nas extremidades da mesma, ou seja, Jabaquara e Santana (cerca de $20 \%$ atribulvel ao metrô); e um crescimento da participação do fator "renda" na determinação do preço do solo proporcional a aumento da renda média familiar das áreas estudadas.

\section{O Impacto sobre a Ocupação do Solo}

O impacto sobre a ocupação do solo, efeito da captação da valorização imobiliária produzida pela linha de metrô, foi avaliado com base em análises estatlsticas (descritivas e discriminantes) aplicadas às características das edificaçōes existentes antes da .mplantação da linha (idade, área construlda, aproveitamento real do lote, valor venal do imóvel, padrāo construtivo) e às áreas edificáveis permitidas pela lei de zoneamento. Os resultados indicaram concentração de demolições nos pólos terciários servidos pela linha de metrô (principalmente em Santana, Vila Mariana e Saúde) e nas áreas com maiores indices legais de aproveitamento do solo (Z3 e Z4).

Os imóveis demolidos caracterizaram-se por lotes com cerca de 700 metros quadrados, 18 metros de frente, 40 metros de fundo, 230 metros quadrados de área construfda ( $1 / 8$ inferior à área permitida pela lei de zoneamento), 21 anos de idade e distantes 700 metros da estação de metrô mais próxima. Uma equação, com classificação correta em $84 \%$ dos casos, mostrou que há condiçōes de se prever a demoliçāo de edificaçōes em função das características ffsicas dos imóveis existentes antes da implantação de linhas de metrô. Essa probabilidade de ocorrência de demoliçōes é função da relação entre a área edificável por lei e aquela edificada, da idade das costruçōes, da área dos lotes e de sua distância às estaçōes da linha.

\section{O Impacto sobre o Uso do Solo}

O impacto sobre o uso do solo, avaliado a partir de dados dos censos de 1970 e 1980 e do cadastro imobiliário da Prefeitura de São Paulo (TPCL), resultou em maior crescimento de edificaçōes residenciais nas extremidades da linha de metrô, sendo apartamentos de alto padrão em Santana e sobrados e apartamentos de padrão médio em
(2) NIGRIEUO, A. Pesquisa Empírica. In: O valor do solo e sua relaçăo com a acessibilidade. (Estudo do impacto da implantação da linha NorteSul do metró de Săo Paulo sobre o mercado imobilliário). Rio de Janeiro, 1977. Dissertaçăo Mestrado - COPPEJUFRJ, p. 76-115.

Conservar para desenvolver. (Estudo sobre as alteraçőes do espaço edificado ao longo da linha Norte-Sul do metró de Săo Paulo). São Paulo, 1987. Tese de Doutorado - FAUUSP. 
Mapa 1




Vila Guilherme e Jabaquara (em bairros próximos e afastados da estação); e maior crescimento de edificações não residenciais nos dois principais pólos terciários atendidos pela linha de metrô, Santana e Vila Mariana.

\section{O Impacto sobre a População}

O impacto sobre a populaçāo da área de estudo, também avaliado com base nos dois censos populacionais citados, traduziu-se em maior crescimento da densidade populacional e de domicnios nas extremidades da linha, Santana e Jabaquara; e maior crescimento da renda média domiciliar em Santana.

Em particular, nos setores censitários onde ocorreu maior número de demoliçōes, concentrados nos pólos Santana, Saúde e Vila Mariana, observou-se uma reduçāo no montante de edificaçōes residenciais e na densidade populacional, acompanhada de aumento na renda média domiciliar. Este resultado pode ser um indicador do crescimento das atividades terciárias nesses locais e/ou do afastamento da população de baixa renda. Ver Mapa 1.

\section{Reflexos das Alterações no Espaço Urbano sobre o Perfil dos Usuários da Linha de Metrô}

As alteraçōes provocadas pela linha Norte-Sul do metrô sobre o espaço urbano têm se refletido sobre o perfil de seus usuários. De fato, comparando dados de pesquisas periódicas realizadas pelo Metrô de Sāo Paulo sobre os usuários da linha, nota-se, na última década, um crescimento da percentagem de passageiros com origem (37\% do total de passageiros, em 1989) ou destino ( $76 \%$ desse total, na mesma data) nos cfrculos de 1.200 metros de raio ao redor das estaçōes, confirmando o adensamento do espaço urbano lindeiro; bem como dos passageiros da classe rica (32\% do total, nessa data), atraídos por esse serviço de transporte coletivo.

\section{Estratégias de Controle do Impacto de Melhorias no Sistema de Transporte sobre o Espaço Urbano}

Se a busca de economias de localização produzidas por maiores nfveis de acessibilidade e a captação da valorização imobiliária resultante de melhorias nesses niveis alicerçam a relação entre o sistema de transporte e o uso e ocupaçāo do solo, o controle do impacto sobre o espaço urbano de intervenções nesse sistema passa pelo controle da realização de tais vantagens econômicas.

A necessidade desse controle não se justifica apenas pela busca de maior justiça social na distribuição dos beneficios indiretos vinculados a investimentos públicos em transporte, mas inclusive pela redução de seus efeitos perversos, como: desequilforios resultantes de aumentos de população e/ou atividades superiores ao nivel da oferta local de serviços urbanos, transporte inclusive; afastamento da população de baixa renda; perda do valor de uso das edificaçōes demolidas precocemente; perda de referenciais urbanos, etc.

A forma tradicional do exerclcio deste controle é a lei de zoneamento, que delimita os coeficientes de aproveitamento do solo e define os usos mais adequados, visando 0 equillbrio na distribuição espacial de população, atividades e serviços públicos. Além deste instrumento, outros foram cogitados, sendo alguns aplicados em cidades brasileiras, tendo em vista sua eficiência em palses do primeiro mundo ${ }^{3}$. A maioria desses instrumentos vincula o pagamento do serviço de transporte nāo apenas aos usuários, com a cobrança da tarifa, mas a todos que indiretamente dele se beneficiam. Ainda há
(3) NIGRIELO A. Fontes alternativas para financiamento do transporte coletivo. A experiencia francesa. Săo Paulo, 1989. Relatórlo de viagem apresentado à EBTU, FAUUSP e METRÓISP. 
os que fazem o Poder Público participar do mercado imobiliário e dessa forma recuperar parte dos beneffcios por ele gerados com os investimentos em transporte ${ }^{4}$. Finalmente, há instrumentos de planejamento que minimizam os impactos negativos envolvidos nesse processo ${ }^{5}$.

\section{"Taxa Transporte"}

Inspirada no "versement transport" francês, a "Taxa Transporte", que está sendo aplicada na cidade de Campinas, garante a participação dos empregadores no financiamento do transporte coletivo urbano. Seu uso fundamenta-se nas externalidades que investimentos no sistema de transporte trazem aos empregadores:

- economias realizadas nos gastos em transporte de seus empregados que os empregadores poderiam ser levados a assumir em encargo, com relação aos deslocamentos domiclio-trabalho, se não houvesse um eficiente sistema de transporte coletivo urbano;

- economias realizadas com a maior mobilidade da mão-de-obra e portanto, com a ampliação desse mercado.

A "Taxa Transporte" é aplicável a empresas acima de determinado número de funcionários, localizadas internamente ao perímetro urbano. O montante cobrado, destinado às entidades de transporte urbano para investimentos no setor, é função de um percentual aplicado à massa salarial paga em cada empresa.

Cabe observar, no entanto, que sob o aspecto de eqüidade, a "Taxa Transporte" apresenta alguns problemas: empresas localizadas na periferia, com um acesso parcial ao sistema de transporte coletivo pagam este imposto da mesma forma que empresas localizadas nas áreas com os maiores graus de acessibilidade. A nivel macroeconômico, este instrumento penaliza as empresas e modifica suas condiçōes de competitividade. Penaliza mais os setores de mão-de-obra intensiva que os de capital intensivo.

\section{Impostos Imobiliários Atualizados}

Na conferência das Naçōes Unidas em Vancouver, em 1976, conclúa-se: "o lucro excessivo resultante do crescimento do valor dos terrenos devido à urbanização e à mudança de uso é uma das causas de concentração de riqueza em māos privadas. A tributação não deve ser considerada apenas como fonte de recursos para a coletividade, mas também como um instrumento poderoso para redistribuir ao conjunto dos habitantes os benefícios dessa valorização"

A cobrança de imposto imobiliário anual pode ser uma técnica de recuperação da valorização resultante de melhorias no sistema de transporte, mas apresenta a seguinte dificuldade: o aumento do valor dos imóveis não é atribulvel exclusivamente à realização desses investimentos públicos; pode ocorrer uma valorização dos imóveis em função de mudanças na legislação urbana e nas condiçōes econômicas e sociais que regem o mercado imobiliário. Ou seja, é necessário um certo cuidado ao atribuir uma vinculação entre o valor venal dos imóveis e a realização dos equipamentos públicos, sendo praticamente impossivel relacionar o montante arrecadado na cobrança do imposto imobiliário com o custo do sistema de transporte e demais infra-estruturas urbanas realizadas pelo Poder Público. 4) NIGRIELLO, A, et alii. Construir o metrô é
também reconstruir a cidade. São Paulo, 1991. METRO̊/SP - NTL.

(5) BOLOGNA. Comune. Per il recupero urbano. Bologna, 1980.

CAMPOS VENUTI, G. Urbanistica e austerità. Milano, Feltrinelli, 1978.
No entanto, o acompanhamento constante dos preços estipulados no mercado imobiliário e a atualização do imposto anual são fundamentais para que o Poder Público recupere e redistribua parte da valorização dos imóveis privados originada por investimentos em transporte. 


\section{Empreendimentos Imobiliários do Poder Público Vinculados ao Sistema de Transporte}

A partir da edificação e comercialização do patrimônio imobiliário vinculado ao sistema de transporte urbano o que se visa recuperar em termos econômicos é a valorizaçăo provocada por investimentos públicos no setor, o preço do solo, o lucro imobiliário sobre esse solo após sua edificaçāo e o lucro imobiliário sobre a área construlda. De forma conjugada a esses efeitos econômicos busca-se a ordenação do espaço urbano, seu adensamento e, em conseqüência, maior utilização da capacidade de transporte oferecida e aumento da receita operacional - importantes metas do planejamento urbano e de transporte.

Para a realização desses empreendimentos imobiliários há diferentes alternativas de associação do setor público com o setor privado, sendo os ganhos de capital proporcionais a seu envolvimento no processo (Empreendimentos Associados).

O emprego dessa estratégia na expansão do sistema de transporte deve ser associado ao estabelecimento de uma polttica de desapropriação que viabilize determinados objetivos econômicos, sociais e urbanisticos.

Assim, em termos econômicos, esta nova polftica deve permitir o pagamento, a longo prazo, dos custos de desapropriaçāo ou, eventualmente, seu repasse.

Em termos sociais esta polf́tica deve garantir maior justiça na distribuiçăo dos beneffcios, possibilitando, nos empreendimentos imobiliários promovidos pelo Poder Público, a participação dos proprietários dos imóveis desapropriados - diretamente ou através de permuta dos imóveis desapropriados por outros do Poder Público, ou financiados por entidades públicas vinculadas a programas habitacionais populares.

Em termos urbanísticos esta nova polftica de desapropriaçāo deve formar um estoque de terra de propriedade do Poder Público, estrategicamente localizado, suporte do processo de recuperação urbana vinculado ao sistema de transporte. Esta estratégia, que vem sendo estudada e testada no Metrô de São Paulo, é prática das empresas de transporte público na França, Canadá, Japão, entre outros palses.

Preservação das Áreas Próximas às Melhorias de Transporte Ocupadas por População de Baixa Renda

A delimitação prévia das áreas ocupadas por população de baixa renda nas imediaçōes de melhorias significativas do sistema de transporte e a adoçāo de uma polftica para a preservação das edificações existentes e fixação de seus habitantes reduzem a demolição das construçōes e a expulsāo da população.

Como diretrizes desta polftica de preservação do espaço urbano são adotadas, entre outras:

- proibir a agregaçāo de lotes;

- evitar mudanças na lei de zoneamento que permitam maiores Índices de aproveitamento dos lotes e usos econômicos mais rentáveis;

- limitar as ocorrências de demoliçāo às construções mais antigas, sem condições de reciclagem. As novas edificaçōes devem respeitar a organização espacial e a tipologia das construções remanescentes;

- apoiar a formação de associação de moradores visando a preservação do espaço edificado e dos demais valores locais. Criar a consciência que "desenvolver" é também "preservar" o que já se possui; 
- criar linhas de financiamento, benefícios fiscais e serviços gratuitos de consultoria visando a preservação das edificaçōes. Criar, previamente, instrumentos de acordo, entre proprietários e inquilinos para o controle dos aluguéis.

Essas diretrizes de controle do espaço urbano têm sido aplicadas, com sucesso, em cidades italianas, francesas e alemãs.

\section{Observação Final}

Alguns instrumentos de controle do espaço urbano, mesmo se desenvolvidos em palses do primeiro mundo, podem orıentar a prática do planejamento urbano em cidades brasileiras. Viabilizam essa transposição de experiências algumas "leis" que expressam relaçōes urbanas comuns a todas as cidades, cuja descoberta é fascinante e cujo emprego no controle do espaço urbano é fundamental. Uma dessas "leis", possivelmente a mais importante, é a da interação entre o transporte e o uso e ocupação do solo. Este artigo visa contribuir para este conhecimento apresentando resultados e considerações apoiados em um caso real da cidade de São Paulo, observado por ocasião da sua primeira linha de metrô. 